\title{
Inequity in Distribution of Psychiatry Trainee Seats and Institutes Across Indian States: A Critical Analysis
}

Ramdas S. Ransing ${ }^{1, \odot ~ G i r i s h ~ A g r a w a l ~}{ }^{2} \quad$ Koustubh Bagul $^{3} \quad$ Krishna Pevekar $^{1}$

\begin{abstract}
Address for correspondence Ramdas S. Ransing, MBBS, MD, Department of Psychiatry, BKL Walawalkar Rural Medical College, Sawarde, Chipalun, Ratnagiri 415606, Maharashtra, India (e-mail: ramdas_ransing123@yahoo.co.in).
\end{abstract}

\begin{abstract}
Background The delivery of mental health services largely depends on the adequacy of human resources. In India, the deficit of psychiatrists is more than $90 \%$ and is one of the major challenges that needs to be tackled to address the huge burden of mental illness. Psychiatry trainee institutes play a vital role in reducing human resource deficit and inequality in delivering mental health care. However, the distribution pattern of psychiatry trainee seats and institutes across Indian states is unknown. Therefore, we estimated the number of psychiatry trainee seats and institutes in each Indian state and union territory (UT).

Materials and Methods In this cross-sectional study, psychiatry trainee seats and institutes were searched on the official web sites of Medical Council of India and National Board of Examinations. The data available on these web sites until December 2019 were included. State-wise data were compared using proportion and percentages. The psychiatry trainee index (PTI) was calculated and compared across Indian states and UTs.

Results Among 221 Indian psychiatry trainee institutes considered in the present study, 116 (52.48\%) were private institutes and 105 (47.51\%) were government institutes. Overall, more psychiatry trainee seats were reported in government institutes ( $n$ $=565,65.89 \%)$ than in private institutes. National PTI was considered fair (0.06), and

Keywords

- psychiatry

- education

- trainee

- India

- deficit based on their PTIs, Indian states and UTs were classified as follows: worst $(n=9)$, poor $(n=8)$, fair $(n=9)$, average $(n=7)$, good $(n=1)$, and excellent $(n=2)$.

Conclusion A huge deficit of psychiatry trainees and institutes exists in more than two-thirds of Indian states and UTs, along with a huge maldistribution of seats. PTI and its distribution across the states and UTs are a crucial indicator of the need to improve the access and equity of mental health care.
\end{abstract}

\section{Introduction}

According to the national mental health survey conducted across 12 Indian states, the prevalence of mental disorders is approximately $10.6 \% .^{1}$ However, a treatment gap of 70 to $92 \%$ exists across these states for different mental disorders. ${ }^{1}$ Human resource deficit, financial constraints, social stigma, poor community participation, ineffective training, knowledge gap among service providers, lack of nongovernment organization/private partnership, and lack of robust monitoring and evaluation (M and $\mathrm{E}$ ) systems are the critical determinants for this treatment gap. ${ }^{2,3}$ Filling these gaps is often difficult but essential for addressing the high burden of mental disorders and for planning adequate mental health
DOI https://doi.org/

10.1055/s-0040-1709973

ISSN 0976-3147.
License terms

()(1) $\Theta \circledast$ 
services. The district mental health program (DMHP) was started as a component of the national mental health program (NMHP) for the decentralization of mental health services, provision of mental health services at the primary care level, and integration of mental health care in the primary health care system. ${ }^{4}$ According to the research conducted by the Indian Council for Market Research, the DMHP was successful in delivering mental health care at the district level. Still, 68 to $98 \%$ patients are treated at a district hospital or mental hospital; however, it was ineffective beyond the district level. ${ }^{5}$ Mental health professionals experience many hurdles in training primary doctors, mainly due to the lack of psychiatry training institutes and trained psychiatrists.

The National Human Right Commission (NHRC)-National Institute of Mental Health and Neurosciences (NIMHANS) report of 1999 urged to transform mental hospitals into postgraduate (PG) training institutes and relaxation to start a PG course in psychiatry. ${ }^{6}$ In September 2015, World Health Organization (WHO) included mental health in sustainable development goals (SDGs). ${ }^{7}$ SDG targets such as universal health coverage and access to safe, effective, quality, and affordable essential health services, including medicines, may not be achieved in some states of India, if data about the unequal distribution of psychiatry trainee seats are not evaluated and if this problem is not addressed adequately. Moreover, deficiency in the number of psychiatrists, trainees, and institutes can delay the implementation of the Mental Health Care Act (MHCA), 2017, and Protection of Children from Sexual Offenses (POCSO) Act, 2012, across India. ${ }^{89}$ Human resource deficit is the single most factor, largely determining the delivery of and accessibility to mental health care. A previous report described the deficit of psychiatrists in Indian states. ${ }^{10-12}$ In 2010, the average national deficit of psychiatrists in India was estimated to be $77 \%$, and one-third of the population exhibited more than $90 \%$ deficit. ${ }^{10}$ The "ideal" number of psychiatrists is 1 psychiatrist per 100,000 populations. ${ }^{6,13}$ However, according to the WHO Global Health Observatory data for 2016, India has 0.292 psychiatrist, 0.796 psychiatric nurse, 0.065 psychiatric social workers, and 0.069 psychologist.,13 In 2019, Garg et al reported that India may have 0.75 psychiatrist per 100,000 populations against the "desired" number, that is, more than 3 psychiatrists per 100,000 populations. ${ }^{14}$ However, they asserted that these numbers are not dependable due to the absence of a reliable and unified system for monitoring the numbers of psychiatrists. ${ }^{14}$ Thus, assessing the number of psychiatrists and any deficit in number in various states becomes difficult.

Thus, we believed that estimating the number of psychiatry trainee seats/institutes across states could be a more reliable, yet an indirect, method for assessing the deficit of psychiatrists. Data for our study were available due to the improved monitoring of the number by the Medical Council of India (MCI) and National Board of Examinations (NBE). Psychiatry education may be suffering from maldistribution of seats/institutes and involvement of the private sector. This maldistribution can affect or delay the implementation of MHCA, 2017; National Mental Health Policy; and the POCSO Act in certain underdeveloped states or union territories (UTs). The present study examined the deficit/distribution of psychiatry trainee seats/institutes and estimated the psychiatry trainee index (PTI) for Indian states.

\section{Materials and Methods}

In this cross-sectional study, two investigators (R. R. and G. A.) independently conducted the online search for psychiatry trainee seats and institutes from July 2019 to November 2019 (-Fig. 1).

The official Web sites of the MCI (https://www.mciindia. org/) and NBE (http://www.natboard.edu.in/) were searched. Institutes offering a PG degree (Doctor of Medicine [MD]; Diplomate of National Board [DNB]) and diploma (Diploma in Psychological Medicine [DPM]) after a medical graduate degree (Bachelor of Medicine and Bachelor of Surgery) were included in the study; the PG degree should be recognized or permitted by the MCI or NBE. MCI or NBE nonapproved courses (e.g., courses offered by College of Physicians and Surgeons of Mumbai and other foreign degrees), a superspecialty degree or fellowship (e.g., Child and adolescent psychiatry), and secondary DNB (post-DPM) were excluded from this study.

In this study, we defined government institutes as those owned and managed by the state government, local self-government (municipal cooperation), or central government and private institutes as those owned, managed, and funded by a private trust, society, or company or nongovernment organizations. The data collected by two investigators (R. R. and G. A.) were checked for any discrepancy which, if present, was rectified by a third investigator (K. B.) after researching the official web sites. Ethical permission was not obtained for this study, as it involved the use of data available in the public domain and no participants.

\section{Statistical Analysis}

Psychiatry trainee seats and institutes were presented in terms of number and percentages. State-wise population data (2018) provided by the Unique Identification Authority of India were considered. ${ }^{15}$ The PTI was calculated using the formula mentioned in - Table $\mathbf{1}$. The PTI of the country was considered "fair" (0.06), and the states were classified accordingly using the cut-off value mentioned in - Table 2 .

\section{Results}

According to the December 2019 data, India had 213 psychiatry training institutes and 868 psychiatry trainee seats which were unevenly distributed across the 29 states and 7 UTs (-Table 2). Of these seats, 116 (53.05\%) were from private institutes and 105 (47.51\%) were from government institutes. However, the number of psychiatry trainee seats ( $n=572,65.89 \%$ ) was higher in government institutes than in private institutes ( $n=296,34.10 \%)$.

Five states (Chhattisgarh, Meghalaya, Nagaland, Arunachal Pradesh, and Mizoram) and four UTs (Andaman and Nicobar Islands, Dadra and Nagar Haveli, Daman and Diu, and Lakshadweep) did not have a psychiatry training institute. Among all states, Karnataka had the highest number of PG training institutes in psychiatry $(n=27)$, followed 


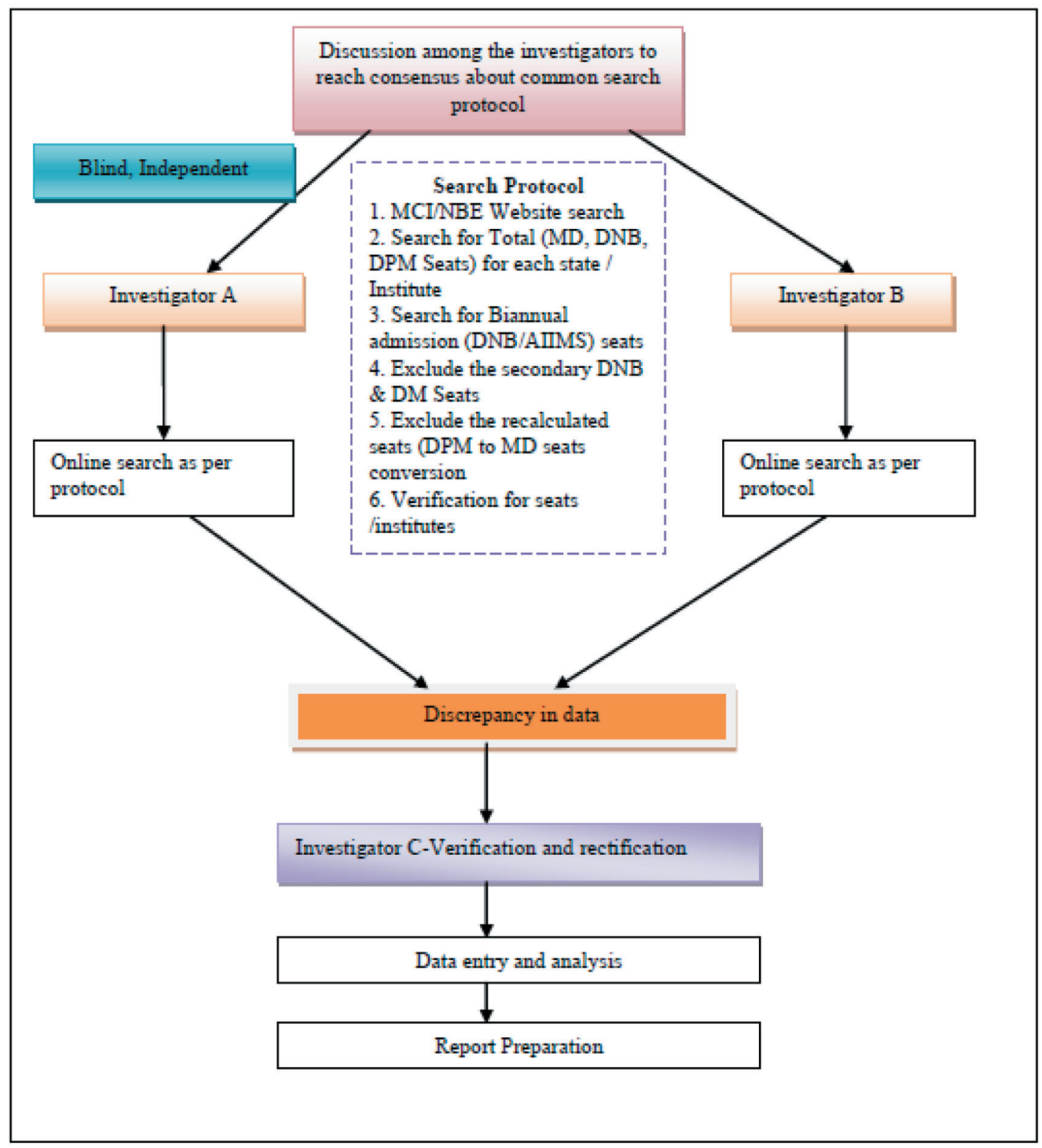

Fig. 1 Methodology flow chart. AlIMS, All India Institute of Medical Sciences; DM, Doctorate of Medicine; DNB, Diplomate of National Board; DPM, Diploma in Psychological Medicine; MCI, Medical Council of India; MD, Doctor of Medicine; NBE, National Board of Examinations.

Table 1 Psychiatry trainee index formula

PTI for a state $=$ number of psychiatry trainee seats in the state per year $\times 100,000 /$ population of the respective state

PTI for the country = number of psychiatry trainee seats in the country per year $\times 100,000 /$ population of the country

by Maharashtra $(n=26)$ and Tamil Nadu $(n=21)$, whereas among UTs, Delhi ( $n=8)$, Puducherry $(n=6)$, and Chandigarh $(n=2)$ had higher number of institutes in a decreasing order.

More number of private institutes than government institutes were reported in Uttarakhand ( $n=2,100 \%)$, Sikkim ( $n=1,100 \%)$, Karnataka ( $n=22,81.48 \%)$, Andhra Pradesh ( $n=12,80 \%$ ), and Telangana $(n=9,69.23 \%)$, and among the UTs, Puducherry had more private institutes $(n=5,83.33 \%)$ than government institutes. On the other hand, a higher number of government institutes than private institutes were reported in Assam ( $n=4,100 \%)$, Jharkhand ( $n=3,100 \%)$, Jammu and Kashmir ( $n=2,100 \%)$, Tripura ( $n=1,100 \%)$, Manipur ( $n=1,100 \%)$, Goa $(n=1,100 \%)$, West Bengal $(n=8,88.88 \%)$, Gujarat ( $n=11,78.57 \%$ ), and Punjab ( $n=4,80.00 \%)$. Majority of PG institutes in the UTs (Chandigarh [ $n=2,100 \%]$ and Delhi $[n=6,75 \%]$ ) were government, except in Puducherry $(n=1,16.66 \%)$.

The number of PG trainee seats was higher in Karnataka ( $n=124)$, Tamil Nadu $(n=87)$, Maharashtra $(n=83)$, Kerala $(n=54)$, and Andhra Pradesh $(n=55)$, and among the UTs, it was higher in Delhi $(n=63)$, Chandigarh $(n=18)$, and Puducherry $(n=15)$.

The distribution of psychiatry trainee seats was not consistent with that of government or private institutes across India. Similar to the UT Puducherry ( $n=11,73.33 \%)$, the state of Uttarakhand ( $n=4,100 \%)$, Sikkim ( $n=3,100 \%)$, Andhra 
Table 2 Distribution of psychiatry training institutes, trainee seats, population and psychiatry trainee index across Indian states and union territories

\begin{tabular}{|c|c|c|c|c|c|c|c|c|}
\hline \multirow[t]{2}{*}{ States } & \multicolumn{3}{|c|}{$\begin{array}{l}\text { Number of psychiatry training } \\
\text { institutes }\end{array}$} & \multicolumn{3}{|c|}{ Post graduate psychiatry trainee seats } & \multirow[t]{2}{*}{$\begin{array}{l}\text { Population as per } \\
2018 \text { UIDAI }\end{array}$} & \multirow{2}{*}{$\begin{array}{l}\text { Psychiatry } \\
\text { trainee } \\
\text { index }\end{array}$} \\
\hline & $\begin{array}{l}\text { Total } \\
(n)\end{array}$ & $\begin{array}{l}\text { Government } \\
n(\%)\end{array}$ & $\begin{array}{l}\text { Private } \\
n(\%)\end{array}$ & Total $(n)$ & $\begin{array}{l}\text { Government } \\
n(\%)\end{array}$ & $\begin{array}{l}\text { Private } \\
n(\%)\end{array}$ & & \\
\hline Uttar Pradesh & 14 & $5(35.71)$ & $9(64.28)$ & 51 & $30(58.82)$ & $21(41.17)$ & $228,959,599$ & 0.022 \\
\hline Maharashtra & 26 & $11(42.30)$ & $15(57.69)$ & 85 & $47(55.29)$ & $38(44.70)$ & $120,837,347$ & 0.070 \\
\hline Bihar & 3 & $2(66.66)$ & $1(33.34)$ & 3 & $2(66.67)$ & $1(33.33)$ & $119,461,013$ & 0.0025 \\
\hline West Bengal & 9 & $8(88.88)$ & $1(11.12)$ & 31 & $29(93.55)$ & $2(6.45)$ & $97,694,960$ & 0.0409 \\
\hline Madhya Pradesh & 7 & $3(42.86)$ & $4(57.14)$ & 24 & $13(54.17)$ & $11(45.83)$ & $82,342,793$ & 0.0267 \\
\hline Rajasthan & 9 & $6(66.67)$ & $3(33.33)$ & 28 & $22(78.57)$ & $6(21.43)$ & $78,230,816$ & 0.0639 \\
\hline Tamil Nadu & 21 & $10(47.61)$ & $11(52.38)$ & 87 & $52(59.77)$ & $35(40.23)$ & $76,481,545$ & 0.113 \\
\hline Karnataka & 27 & $5(18.51)$ & $22(81.48)$ & 124 & $59(47.58)$ & $65(52.41)$ & $66,165,886$ & 0.187 \\
\hline Gujarat & 14 & $11(78.57)$ & $3(21.42)$ & 45 & 38 (84.44) & $7(15.55)$ & $63,907,200$ & 0.070 \\
\hline Andhra Pradesh & 15 & $3(20.00)$ & $12(80.00)$ & 55 & 25 (45.45) & $30(54.55)$ & $52,883,163$ & 0.104 \\
\hline Odisha & 4 & $2(50.00)$ & $2(50.00)$ & 13 & $7(53.85)$ & $6(46.15)$ & $45,429,399$ & 0.028 \\
\hline Telangana & 13 & $4(30.76)$ & $9(69.23)$ & 42 & $21(50.00)$ & $21(50.00)$ & $38,472,769$ & 0.109 \\
\hline Jharkhand & 3 & $3(100.00)$ & $0(0.00)$ & 29 & $29(100.00)$ & $0(0.00)$ & $37,329,128$ & 0.077 \\
\hline Kerala & 18 & $8(44.44)$ & $10(55.55)$ & 56 & $33(58.92)$ & $23(41.07)$ & $35,330,888$ & 0.158 \\
\hline Assam & 4 & $4(100)$ & $0(0)$ & 30 & $30(100.00)$ & $0(0.00)$ & $34,586,234$ & 0.0868 \\
\hline Punjab & 5 & $4(80.00)$ & $1(20.00)$ & 15 & $12(80.00)$ & $3(20.00)$ & $29,611,935$ & 0.0506 \\
\hline Chhattisgarh & 0 & $0(0.00)$ & $0(0.00)$ & 0 & $0(0.00)$ & $0(0.00)$ & $28,566,990$ & 0 \\
\hline Haryana & 3 & $1(33.33)$ & $2(66.67)$ & 17 & $12(70.59)$ & $5(29.41)$ & $27,388,008$ & 0.062 \\
\hline Delhia & 8 & $6(75.00)$ & $2(25.00)$ & 63 & $61(96.82)$ & $2(3.17)$ & $18,345,784$ & 0.34 \\
\hline $\begin{array}{l}\text { Jammu and } \\
\text { Kashmir }{ }^{a, b}\end{array}$ & 2 & $2(100.00)$ & $0(0.00)$ & 11 & $11(100.00)$ & $0(0.00)$ & $13,635,010$ & 0.080 \\
\hline Uttarakhand & 2 & $0(0.00)$ & $2(100.00)$ & 4 & $0(0.00)$ & $4(100.00)$ & $11,090,425$ & 0.036 \\
\hline $\begin{array}{l}\text { Himachal } \\
\text { Pradesh }\end{array}$ & 2 & $1(50.00)$ & $1(50.00)$ & 5 & $3(60.00)$ & $2(40.00)$ & $7,316,708$ & 0.068 \\
\hline Tripura & 1 & $1(100.00)$ & $0(0.00)$ & 3 & $3(100.00)$ & $0(0.00)$ & $4,057,847$ & 0.073 \\
\hline Meghalaya & 0 & $0(0.00)$ & $0(0.00)$ & 0 & $0(0.00)$ & $0(0.00)$ & $3,276,323$ & 0 \\
\hline Manipur & 1 & $1(100.00)$ & $0(0.00)$ & 3 & $3(100.00)$ & $0(0.00)$ & $3,008,546$ & 0.099 \\
\hline Nagaland & 0 & $0(0.00)$ & $0(0.00)$ & 0 & $0(0.00)$ & $0(0.00)$ & $2,189,297$ & 0 \\
\hline Goa & 1 & $1(100.00)$ & $0(0.00)$ & 8 & $8(100.00)$ & $0(0.00)$ & $1,542,750$ & 0.51 \\
\hline $\begin{array}{l}\text { Arunachal } \\
\text { Pradesh }\end{array}$ & 0 & $0(0.00)$ & $0(0.00)$ & 0 & $0(0.00)$ & $0(0.00)$ & $1,528,296$ & 0 \\
\hline Puducherrya & 6 & $1(16.66)$ & $5(83.33)$ & 15 & $4(26.67)$ & $11(73.33)$ & $1,375,592$ & 1.09 \\
\hline Mizoram & 0 & $0(0.00)$ & $0(0.00)$ & 0 & $0(0.00)$ & $0(0.00)$ & $1,205,974$ & 0 \\
\hline Chandigarha $^{a}$ & 2 & $2(100.00)$ & $0(0.00)$ & 18 & $18(100.00)$ & $0(0.00)$ & $1,126,705$ & 1.59 \\
\hline Sikkim & 1 & $0(0.00)$ & $1(100.00)$ & 3 & $0(0.00)$ & $3(100.00)$ & 671,720 & 0.446 \\
\hline $\begin{array}{l}\text { Andaman and } \\
\text { Nicobar Islands a }\end{array}$ & 0 & $0(0.00)$ & $0(0.00)$ & 0 & $0(0.00)$ & $0(0.00)$ & 419,978 & 0 \\
\hline $\begin{array}{l}\text { Dadra and Nagar } \\
\text { Haveli a }\end{array}$ & 0 & $0(0.00)$ & $0(0.00)$ & 0 & $0(0.00)$ & $0(0.00)$ & 378,979 & 0 \\
\hline Daman and Diua & 0 & $0(0.00)$ & $0(0.00)$ & 0 & $0(0.00)$ & $0(0.00)$ & 220,084 & 0 \\
\hline Lakshadweep ${ }^{a}$ & 0 & $0(0.00)$ & $0(0.00)$ & 0 & $0(0.00)$ & $0(0.00)$ & 71,218 & 0 \\
\hline Total & 221 & $105(47.51)$ & $116(52.48)$ & 868 & $572(65.89)$ & $296(34.10)$ & $1,335,140,909$ & 0.065 \\
\hline
\end{tabular}

Abbreviation: UIDAI, unique identification authority of India.

aunion territories.

${ }^{b}$ Considered as a state for this study (Data was not available UT wise). However, the state has been divided into two union territories (Jammu and Kashmir, and Ladkh since October 2019) 
Pradesh $(n=30,54.55 \%)$, and Karnataka ( $n=65,52.41 \%)$ had more PG trainee seats in private institutes. Conversely, the states of Assam, Jharkhand, Jammu and Kashmir, Tripura, Manipur, and Goa and the UT of Chandigarh had all trainee seats from government institutes alone. In addition, West Bengal ( $n=29,93.54 \%)$, Gujarat ( $n=36,83.72 \%$ ), Rajasthan ( $n=22,78.52 \%)$, Punjab ( $n=10,76.92 \%)$, Haryana ( $n=12,70.58 \%)$, and Bihar $(n=2,66.67 \%)$ had more seats in government institutes.

- Table 3 depicts the PTI and grades of PTI. Among the six densely populated Indian states, five states had a poor PTI (Uttar Pradesh [0.022], Bihar [0.0025], West Bengal [0.0409], Madhya Pradesh [0.0267], and Rajasthan [0.0639]), whereas one state (Maharashtra [0.070]) had a fair PTI. Among the UTs with a dense population, Delhi had an average PTI (0.34), whereas Puducherry (1.09) and Chandigarh (1.59) had excellent PTIs.

- Table 3 and - Fig. 2 present the categorization of Indian states and UTs on the basis of PTI. Of the 29 states, 26 had fair to worst PTIs, whereas only 10 had average to excellent PTIs. Only two UTs (Puducherry and Chandigarh) had excellent PTIs, and only one state (Goa) had a good PTI.

\section{Discussion}

The present study reported that Puducherry and Chandigarh had excellent PTIs, whereas Goa had a good PTI. These findings are supported and correlated with those in a 2010 report by Thirunavukarasu and Thirunavukarasu, which stated that Chandigarh (200\%), Goa (86\%), and Puducherry (50\%) had a surplus of psychiatrists. ${ }^{10}$ Although Delhi

Table 3 Categorization of the states and union territories on the basis of PTI (psychiatry training seats/per 0.1 million population)

\begin{tabular}{|c|c|c|}
\hline $\begin{array}{l}\text { Grades, no. of } \\
\text { states }\end{array}$ & $\begin{array}{l}\text { PTI } \\
\text { classification }\end{array}$ & States and UTs \\
\hline Worst $(n=9)$ & $0.00-0.0009$ & $\begin{array}{l}\text { Chhattisgarh, Meghalaya, } \\
\text { Nagaland, Arunachal } \\
\text { Pradesh, Mizoram, Andaman } \\
\text { and Nicobar Islands, Dadra } \\
\text { and Nagar Haveli, Daman } \\
\text { and Diu, Lakshadweep }\end{array}$ \\
\hline Poor $(n=8)$ & $0.001-0.049$ & $\begin{array}{l}\text { Bihar, Uttar Pradesh, } \\
\text { Odisha, Madhya Pradesh, } \\
\text { West Bengal, Rajasthan, } \\
\text { Uttarakhand, Punjab }\end{array}$ \\
\hline Fair $(n=9)$ & $0.05-0.099$ & $\begin{array}{l}\text { Haryana, Gujarat, Himachal } \\
\text { Pradesh, Maharashtra, } \\
\text { Tripura, Jharkhand, Jammu } \\
\text { and Kashmir, Assam, } \\
\text { Manipur }\end{array}$ \\
\hline Average $(n=7)$ & $0.1-0.5$ & $\begin{array}{l}\text { Andhra Pradesh, Telangana, } \\
\text { Tamil Nadu, Kerala, } \\
\text { Karnataka, Delhi, Sikkim, }\end{array}$ \\
\hline $\operatorname{Good}(n=1)$ & $0.5-0.99$ & Goa \\
\hline Excellent $(n=2)$ & $>1.0$ & Puducherry, Chandigarh \\
\hline
\end{tabular}

Abbreviations: PTI, psychiatry trainee index; UT, union territory.
(13\%) had a surplus of psychiatrists, it had an average PTI. UTs with national institutes such as All India Institute of Medical Sciences (AIIMS, New Delhi), Jawaharlal Institute of Postgraduate Medical Education and Research (Puducherry), and Post Graduate Institute of Medical Education and Research (PGIMER, Chandigarh) had good to excellent PTIs, and thus, they had a surplus of psychiatrists (more teaching faculty and residents). This also highlights the role of national institutes in psychiatry training and mental health care delivery.

Among nine states having worst PTIs, all states had a psychiatrist deficit of more than $75 \%$ except Mizoram which had a 50 to $74 \%$ psychiatrist deficit. Of the eight states and UTs having poor PTIs, seven states, excluding Punjab, had a psychiatrist deficit of more than $75 \%$. Despite having poor to worst PTIs, Punjab and Mizoram had minimum psychiatrist deficits compared with other states. Of the nine states with fair PTIs, seven had more than $75 \%$ deficit, except Maharashtra and Tripura, which had a psychiatrist deficit of less than $50 \%$ and 50 to $74 \%$, respectively. This could be due to the migration of psychiatrists from other states to Punjab and Maharashtra and training initiatives by NIMHANS for northeastern states (Tripura and Mizoram).

Of the seven states with average PTIs, four (except Andhra Pradesh, Telangana, and Delhi) had a psychiatrist deficit of 50 to $74 \%$. Delhi had surplus psychiatrists, whereas Andhra Pradesh and Telangana had a psychiatrist deficit of more than $74 \%$. The PTI predicted a $77.77 \%$ deficit or surplus of psychiatrists for all 28 states.

One psychiatry trainee seat indicates the availability of at least four full-time psychiatrists in that institute or state (as per the requirement of the $\mathrm{MCI}$ or $\mathrm{NBE}$ regulation; - Table 4). . $^{16,17}$

Due to regulation from the MCI or NBE authority, most psychiatry trainee institutes offer specialty clinics or services for specific conditions (e.g., schizophrenia, dementia, and addiction) and community awareness programs and clinics. The absence of psychiatry trainee seats in states implies the absence of minimal requirements to start a course and services.

Therefore, the PTI can be used as a proxy index to interpret the deficit or surplus of psychiatrists until the central/ state government or national association of psychiatrist attempts to make a reliable record of practicing psychiatrists in respective states. The PTI can be beneficial in curbing the human resource deficit and planning alternative short- and medium-term interventions to ensure primary mental health care in a state with a worst to poor PTI. The following evidence-based interventions can improve the PTI ( Table 5) ${ }^{18,19}$ Increasing psychiatry trainee seats without considering the PTI can further increase inequality in psychiatry care. Evidently, few districts and metropolitan cities in Indian states have more psychiatry trainee seats than other districts. However, establishing institutes for training manpower after referring to the PTI data can reduce the inequality and increase accessibility to care in those district or states.

The Indian government is striving to improve mental health care services with almost overlapping objectives 

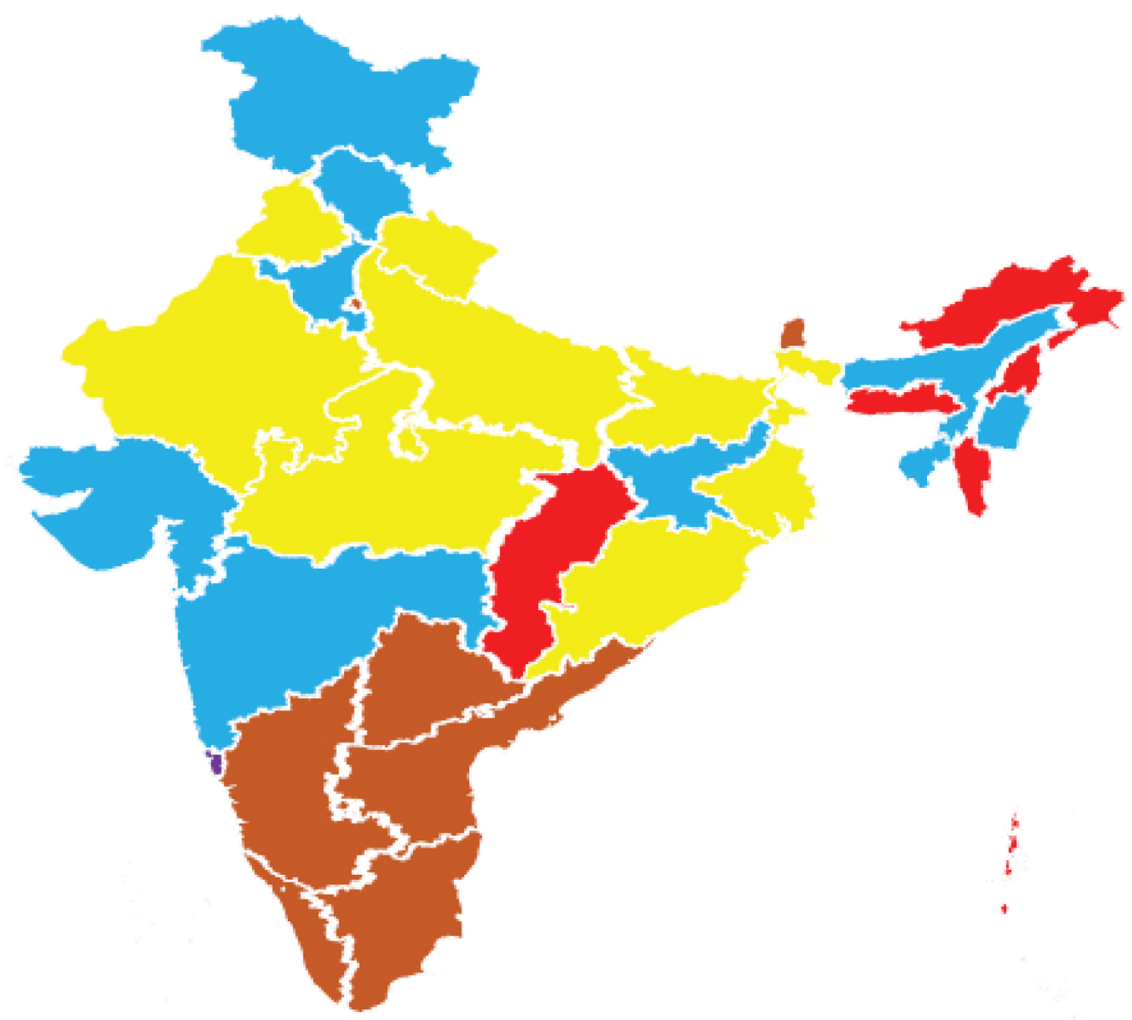

\section{Legend:}

\begin{tabular}{|l|l|l}
\hline Color Code & \multicolumn{1}{|c|}{ Description of state } & Grades of PTI \\
\hline & States or UTs with Post graduation seats $(0.00-0.0009 / 1,00,000$ population) & Worst \\
\hline & States or UTs with Post graduation seats $(0.001-0.049) / 1,00,000$ population & Poor \\
\hline & States or UTs with Post graduation seats $(0.05-0.099) / 1,00,000$ population & Fair \\
\hline & States or UTs with Post graduation seats $(0.1-0.5) / 1,00,000$ population & Average \\
\hline & States or UTs with Post graduation seats $(0.5-0.99) / 1,00,000$ population & Good \\
\hline & States or UTs with Post graduation seats $(>1.0) / 1,00,000$ population & Excellent \\
\hline
\end{tabular}

Fig. 2 Categorization of the states and union territories on the basis of PTI. PTI, Psychiatry Trainee Index.

Table 4 Trainee seats and requirement of staff/psychiatrists (MCl/NBE regulation)

\section{The type of psychiatry trainee seat: number of psychiatrists required}

MD seat: total (4): professor (1), associate professor(1), assistant professor(1), and senior resident (1)

DNB seat: Total (4): senior consultant (1), junior consultant (1), and senior resident (2)

Abbreviations: DNB. Diplomate of National Board; MCI, Medical Council of India; MD, Doctor of Medicine; NBE, National Board of Examinations. Note: all faculty members should work full-time as per the MCI and NBE regulations.

through the three nationwide plans, namely, MHCA, 2017; NMHP; and National Mental Health Policy. ${ }^{20-22}$ However, implementing these plans can be challenging due to the scarcity of psychiatrists/human resources (mental health professionals and administrative staffs, respectively), financial constraints, knowledge gap among service providers, and social stigma. ${ }^{23}$ Capacity building and training mental health professionals are two of long-term strategies for overcoming this scarcity. ${ }^{10}$ In this context, the number of psychiatry trainee institutes has a vital impact on improving mental health services.

In India, 868 new psychiatrists are trained annually, which is considerably lower to achieve the ideal number of psychiatrists (at least 1.0 psychiatrist per 100,000 populations) and to overcome the deficit of psychiatrists. Moreover, an ideal or a desired number may not be useful in a region having high burden of mental disorders and substance use, and in conflict-affected states. More than one-third of Indian psychiatrists often prefer migrating to developed countries, although 
Table 5 The PTI and possible interventions for improvement

\begin{tabular}{|l|l|}
\hline PTI & $\begin{array}{l}\text { Recommended interventions for } \\
\text { policymakers and stakeholders }\end{array}$ \\
\hline poor to & $\begin{array}{l}\text { Provision of training support from national } \\
\text { institutes (reservation in MD/DNB seats in } \\
\text { national institutes) and training of primary } \\
\text { healthcare physicians, strengthening of existing } \\
\text { infrastructure for future (long-term-ideal), } \\
\text { and implementation of PPP models, central } \\
\text { government-state government private model, } \\
\text { project ECHO, healthcare worker-based } \\
\text { collaborative models, and Bellary model, and } \\
\text { availability of an in-service quota for PG seats }\end{array}$ \\
\hline Fair to & $\begin{array}{l}\text { Provision of training for primary healthcare } \\
\text { physicians; strengthening of existing } \\
\text { infrastructure; implementation of PPP models, } \\
\text { project ECHO, healthcare worker-based } \\
\text { collaborative models, and Bellary model; and } \\
\text { availability of in-service quota for PG seats, and } \\
\text { fellowship or short-term training programs in } \\
\text { specialties of psychiatry such as addiction and } \\
\text { geriatric psychiatry (based on disease burden) }\end{array}$ \\
\hline $\begin{array}{l}\text { Good to } \\
\text { excellent }\end{array}$ & $\begin{array}{l}\text { Initiation of training activities to support states } \\
\text { with a poor PTI; increase in specialty of the } \\
\text { fellowship course in disorder-prevalent areas; } \\
\text { implementation of the Bellary model; and start } \\
\text { specialty courses such as MD or fellowship in } \\
\text { addiction psychiatry, geriatric psychiatry, and } \\
\text { child and adolescent psychiatry }\end{array}$ \\
\hline
\end{tabular}

Abbreviations: DNB. Diplomate of National Board; MD, Doctor of Medicine; PG, postgraduate; PPP, private-public partnership; PTI, psychiatry trainee index.

detailed data regarding their migration are unavailable for analysis. This further increases the human resource deficit for mental health. ${ }^{24}$

According to our findings, more than half of the psychiatry trainee institutes are under the private sector in the country. Many states and UTs (Uttarakhand, Sikkim, Karnataka, Andhra Pradesh, Telangana, and Pondicherry) had more private institutes, which is alarming because privatization of medical education increases not only the cost of medical education but also that of medical care. ${ }^{25}$ Privatization can also affect provision of mental health services in semiurban, rural, and remote areas and to people with a middle- to low-socioeconomic status. The ministry of health and family welfare's reply to a right to information query revealed that more psychiatrists work in the private sector in Uttarakhand, Karnataka, Andhra Pradesh, and Telagana. ${ }^{26}$ This fact supports our view that mental health services could be difficult to access for poor people from states with more private institutes despite having adequate human resources. On the other hand, private institutes through the private-public partnership (PPP) model can strengthen the training, education, and delivery of mental health services beyond the district level under the DMHP. The PPP model has higher efficiency and accountability and improves the accessibility and reachability to services, along with equity and quality. ${ }^{27}$ However, the lack of a policy-driven strategy; financial delays from the government; and capacity to design, contract, and monitor the PPP model are the major reasons for previous failures. ${ }^{27}$
Therefore, these pros and cons should be considered prior to implementing the PPP model for mental healthcare.

The states and UTs (Assam, Jharkhand, Jammu and Kashmir, Tripura, Manipur, Goa, West Bengal, and Gujarat, and Punjab, Chandigarh, and Delhi) with more government institutes may have the potential to deliver mental health services to underprivileged sectors in an effective and a comprehensive manner. However, other important constraints such as lack of finance, social stigma, lack of community participation, lack of training, and lack of robust monitoring and evaluation ( $M$ and $E$ ) systems need to be addressed effectively.

The states and UTs (Chhattisgarh, Meghalaya, Nagaland, Arunachal Pradesh, and Mizoram, and Andaman and Nicobar Islands, Dadra and Nagar Haveli, Daman and Diu, and Lakshadweep) without any PG seats or institutes (government or private) will not be able to effectively execute the MHCA, 2017; NMHP; and National Mental Health Policy. Mental health services can be expensive and difficult to access in the underprivileged, rural, and tribal regions of these states. Additional support from national institutes such as NIMHANS as a short-term strategy can help them to build capacity. Recently, NIMHANS has made the provision of few psychiatry trainee seats under the "North Eastern Domicile Category" to the states of Arunachal Pradesh, Chhattisgarh, Jammu and Kashmir, Manipur, Meghalaya, Mizoram, Nagaland, Sikkim, Tripura, and Uttarakhand. ${ }^{28}$ As a long-term measure, a PG psychiatry course should be urgently developed or started in these states. Meanwhile, national institutes, such as NIMHANS, PGIMER, and AIIMS, should increase the number of seats (quota or in service) for these states and UTs. NIMHANS has initiated short-term strategies, such as training for general practitioners (3-month course), and midlevel health care service providers such as the NIMHANS ECHO model. ${ }^{3,29,30}$ However, the success of these training strategies is often limited due to lack of organizational support for primary care physicians/service providers, lack of financial support, and poor attendance in training sessions. ${ }^{10}$

Despite having more private psychiatry training institutes, total seats in government institutes are higher in India. However, this figure may have changed due to new MCI rules (increase in PG psychiatry seats and conversion of diploma seats into degree seats) in the past 2 years. ${ }^{31,32}$ Previously, psychiatry trainee seats in private institutes were more than those in government institutes.

Having PG trainee institutes or seats across states and UTs is crucial from training, education, and capacity-building perspectives. However, to achieve mental health for all Indian citizens, these seats should proportionate to the population and burden of mental illness. Therefore, readers, researchers, and policymakers should focus on the PTI for better implementation of the program.

Out study findings suggest that implementing the NMHP or mental health services in existing scenarios can be fragmented and variable, leading to different levels of coverage and access to mental health care. Although short-term approaches are beneficial, more efforts are required to train psychiatry graduates in particular states, thereby improving 
Table 6 Recommendation to stakeholders and policymakers on the basis of state-specific trends of the PTI and burden of mental disorders (with examples)

\begin{tabular}{|c|c|c|c|}
\hline States & $\begin{array}{l}\text { Prevalence of } \\
\text { mental disorders }{ }^{1}\end{array}$ & PTI & Suggested strategies \\
\hline $\begin{array}{l}\text { Kerala, Tamil } \\
\text { Nadu, and } \\
\text { Andhra Pradesh }\end{array}$ & $\begin{array}{l}\text { Depressive disorder } \\
(>3,750 / 100,000)\end{array}$ & Average & $\begin{array}{l}\text { Interventions to reduce the disease-specific burden: provision of disease- } \\
\text { specific training during PG courses; support to states having lower PTIs and } \\
\text { higher disease burden (e.g., Orissa) through the central government-state } \\
\text { government model in training; start of fellowship courses in mood disorders; } \\
\text { and provision of opportunities for research }\end{array}$ \\
\hline Odisha & $\begin{array}{l}\text { Depressive disorder } \\
(>3,750 / 100,000)\end{array}$ & Poor & $\begin{array}{l}\text { Intervention to improve the PTI: provision of training support from national } \\
\text { institutes (reservation in MD/DNB seats in national institutes); implementa- } \\
\text { tion of PPP PG training models; and availability of in-service quota for } \\
\text { PG seats } \\
\text { Addressing the disease burden: } \\
\text { Provision of training for primary healthcare physicians; strengthening of } \\
\text { existing infrastructure; and implementation of PPP models, central govern- } \\
\text { ment-state government private model, project ECHO for depression, } \\
\text { healthcare worker-based collaborative models, and Bellary model }\end{array}$ \\
\hline $\begin{array}{l}\text { Uttar Pradesh, } \\
\text { Madhya } \\
\text { Pradesh, Bihar, } \\
\text { and Assam }\end{array}$ & $\begin{array}{l}\text { Idiopathic develop- } \\
\text { mental intellectual } \\
\text { disability (prevalence } \\
>5,000 \text { per } 100,000 \text { ) }\end{array}$ & $\begin{array}{l}\text { Poor to fair } \\
\text { (Assam) }\end{array}$ & $\begin{array}{l}\text { Intervention to improve the PTI: provision of training support from national } \\
\text { institutes (reservation in MD/DNB seats in national institutes); implementa- } \\
\text { tion of PPP PG training models; and availability of in-service quota for } \\
\text { PG seats } \\
\text { Addressing the disease burden: provision of PG training focused on pre- } \\
\text { ventive psychiatry (nutrition or genetic counseling); provision of training of } \\
\text { primary healthcare physicians; strengthening of existing infrastructure; and } \\
\text { implementation of project ECHO for intellectual disability, PPP models, cen- } \\
\text { tral government-state government private model, health care worker-based } \\
\text { collaborative models, and Bellary model }\end{array}$ \\
\hline $\begin{array}{l}\text { Sikkim and } \\
\text { Kerala }\end{array}$ & $\begin{array}{l}\text { Prevalence }<3,000 \\
\text { per } 100,000)\end{array}$ & Average & $\begin{array}{l}\text { Provision of training support to PG students from poor to low PTI states and } \\
\text { higher disease prevalence; focus on disorders or conditions prevalent in a } \\
\text { state (e.g., depression); development of a brief intervention }\end{array}$ \\
\hline
\end{tabular}

Abbreviations: DNB. Diplomate of National Board; ECHO, Extension for Community Healthcare Outcomes; MD, Doctor of Medicine; PG, postgraduate; PPP, private-public partnership; PTI, Psychiatry Trainee Index.

the accessibility and affordability of mental health services in those states, along with the reduction of social stigma.

The state-specific trends of the PTI reported herein, along with the burden of mental disorders published in 2020 , could more effectively guide in addressing the burden of mental disorders in India by using appropriate policies and health system responses (- Table $\mathbf{6}$ ). ${ }^{33}$ Thus, we recommend that a state having an average to excellent PTI and higher disease prevalence should take initiatives to start specialty courses, such as a fellowship or certificate in addiction, or geriatric psychiatry. This will help to reduce the disease burden and provide support to other states. In addition, these states can help states with higher disease prevalence but lower PTIs through the training of health care workers and development of brief interventions. In states with high disease prevalence and low PTIs, stepped care and matched care approaches should be used to reduce the disease burden and provide education to health care service providers. ${ }^{34}$ Similarly, states with low disease prevalence and low PTIs should identify challenges in terms of disease, stigma, financial constraints, and other barriers in implementing mental health services. Therefore, PG training should focus on resolving state-specific challenges related to mental health care as this would empowering the states.

Awareness regarding the state-specific burden of diseases provides direction to state and central governments in establishing training centers (e.g., fellowship, certificate, or
Doctorate of Medicine [DM]) in the field of child, geriatric, or addiction psychiatry, which can in turn improve PG training quality and boost research and specialist training. However, inadequate number of practicing general psychiatrists and inadequate number of teaching psychiatric faculties in medical colleges make provision of primary care psychiatry in states with poor to worst PTIs difficult. ${ }^{35}$ The increase in superspecialty courses (DM) can lead to further deficit of general psychiatrists. Providing 1-year postdoctoral fellowships through the NBE or MCI in all desirable subspecialties of psychiatry can be a promising solution.

- Table 6 presents recommendations based on disease prevalence and PTI. Other factors such as social stigma, financial constraints, and poor infrastructure for mental health care are other vital determinants in implementing these strategies.

\section{Strengths and Limitations}

This the first comprehensive study reporting the number of psychiatry trainee seats/institutes and their distribution across Indian states and UTs. Findings of this study are important for researchers, medical teachers, and policymakers to develop and implement efficient mental health care services on the basis of disparity and human resource deficiency across Indian states. These data can help in prioritizing mental health service delivery either through 
the government or private sector. In this study, we reported the PTI as a proxy index for determining the number of psychiatrists for states. This index can be beneficial for reporting the deficit or surplus of psychiatrists in states in comparison with the complicated and unreliable estimation of deficit of psychiatrists in previous reports.

Our study has limitations because we included only data available on the NBE and MCI web sites. The PG trainee data undergo frequent changes. Moreover, courses from foreign universities and courses run by the College of Physicians and Surgeons of Mumbai or DPM (approved by the Maharashtra Medical Council, but not by the MCI) were not included in this report. As the study was focused on assessing the PTI only across states, we did not discuss the PTI in metropoli$\tan$ cities. Additionally, the availability of trainee seats in a state does not reflect the availability of trained manpower in that state in future because most of the trainee seats are available under national institutes (state and center quotas).

Brain drain to countries, such as the United Kingdom, Australia, the United States of America, and other countries, for training in psychiatry or practice was not accounted due to lack of availability of records. Therefore, the PTI may not be an ideal index for the availability of psychiatric care and services. However, it can be useful in improving psychiatry training in the country. In future, more such indices for measuring psychiatry education, training, and mental health services should be explored.

The present article mainly focuses on psychiatrist trainee seats; however, data regarding allied mental health professionals, such as social work trainees, psychologists, and mental health professionals, should be considered while interpreting the findings, as they are also crucial for improving mental health services in India. A huge difference exists in terms of fees among private and government medical colleges, and this difference affects the cost-effectiveness of health care at a larger scale. ${ }^{36}$ However, in the present study, no attempts were made to determine the cost-effectiveness of mental health services.

\section{Conclusion}

In India, there is a huge deficit and disparity of psychiatry trainee seats and institutes in more than two-thirds of Indian states and UTs. The PTI can be considered as a proxy marker for analyzing and predicting the deficit or surplus of psychiatrists. For providing basic, affordable, and accessible mental health care across India, understanding the complex interaction of population density, prevalence of substance use disorder, maldistribution of psychiatry trainee seats, and migration of people across states is required. Implementing mental health services in the form of mental health plans, programs, and strategies are not only difficult but currently seem impossible in certain states due to the nonavailability of training institutes and adequate human resources.

\section{Funding}

None.

\section{Conflict of Interest}

R.S.R. reports grants from Indian Council of Medical Research for research project on perinatal depression, outside the submitted work.

\section{Acknowledgments}

The authors would like to express their sincere thanks and gratitude to Prof. Smita Deshpande for sharing her views and comments on initial draft of the manuscript of this article.

\section{References}

1 Murthy RS. National mental health survey of India 2015-2016. Indian J Psychiatry 2017;59(1):21-26

2 Gupta S, Sagar R. National mental health programmeoptimism and caution: a narrative review. Indian J Psychol Med 2018;40(6):509-516

3 Ransing R, Kukreti P, Deshpande S, et al. Perinatal depression-knowledge gap among service providers and service utilizers in India. Asian J Psychiatr 2020;47:101822

4 Singh OP. District mental health program - need to look into strategies in the era of Mental Health Care Act, 2017 and moving beyond Bellary Model. Indian J Psychiatry 2018;60(2):163-164

5 GuptaS, Sagar R. National Mental Health Programme-Optimism and Caution: A Narrative Review. Indian J Psychol Med 2018; 40(6):509-516. doi:10.4103/IJPSYM.IJPSYM_191_18

6 Murthy P, Isaac MK. Five-year plans and once-in-a-decade interventions: Need to move from filling gaps to bridging chasms in mental health care in India. Indian J Psychiatry 2016;58(3):253-258

7 Votruba N, Thornicroft G; Funda Mental SDG Steering Group. Sustainable development goals and mental health: learnings from the contribution of the FundaMentalSDG global initiative. Glob Ment Health (Camb) 2016;3:e26

8 Math SB, Gowda GS, Basavaraju V, et al. Cost estimation for the implementation of the Mental Healthcare Act 2017. Indian J Psychiatry 2019;61(Suppl 4):S650-S659

9 Moirangthem S, Kumar NC, Math SB. Child sexual abuse: issues \& concerns. Indian J Med Res 2015;142(1):1-3

10 Thirunavukarasu M, Thirunavukarasu P. Training and national deficit of psychiatrists in India - a critical analysis. Indian J Psychiatry 2010;52(Suppl 1):S83-S88

11 Chadda RK, Sood M. General hospital psychiatry in India: History, scope, and future. Indian J Psychiatry 2018;60(Suppl 2): S258-S263

12 Yerramilli S, Murty YSS. Psychiatric education in India: need for reforms. Arch Mental Health 2012;13(1):17-22

13 World Health Organisation Global Health Observatory (GHO) data. Psychiatrists and nurses (per 100000 population). Available at: https://www.who.int/gho/mental_health/human_ resources/psychiatrists_nurses/en/. Accessed March 19, 2020

14 Garg K, Kumar CN, Chandra PS. Number of psychiatrists in India: baby steps forward, but a long way to go. Indian J Psychiatry 2019;61(1):104-105

15 Unique Identification Authority of India2018. State/UT wise Aadhaar Saturation: 15th January, 2020. Available at: https:/ uidai.gov.in/images/state-wise-aadhaar-saturation.pdf. Accessed March 19, 2020

16 Jilowa CS, Meena PS, Jain M, et al. Attitude of undergraduate medical students toward psychiatry: A cross-sectional comparative study. Ind Psychiatry J 2018;27(1):124-130

17 Vries MJ, Bouman HJ, Olie RH, et al. Determinants of agreement between proposed therapeutic windows of platelet 
function tests in vulnerable patients. Eur Heart J Cardiovasc Pharmacother 2017;3(1):11-17

18 Balamurugan G, Radhakrishnan G, Vijayarani M. Models and roles in national mental health programme. Indian J Psychiatry Nurse 2019;16(1):52-54

19 Waraich BK, Raj L, Chavan BS, Badhan R, Panda S. Decentralisation of mental health services under DMHP. Indian J Psychiatry 2003;45(3):161-165

20 Math S, Basavaraju V, Harihara S, et al. Mental Healthcare Act 2017- aspiration to action. Indian J Psychiatry 2019;61(10): 660-666

21 Singh OP. National mental health policy of India-new pathways new hope-a journey on enchanted path. Eastern J Psychiatry $2017 ; 18(2)$

22 Gupta S, Sagar R. National mental health programmeoptimism and caution: a narrative review. Indian J Psychol Med 2018;40(6):509-516

23 Math SB, Basavaraju V, Harihara SN, et al. Mental Healthcare Act 2017-aspiration to action. IndianJPsychiatry 2019;61(Suppl4): S660-S666

24 Jenkins R, Kydd R, Mullen P, et al. International migration of doctors, and its impact on availability of psychiatrists in low and middle income countries. PLoS One 2010;5(2):e9049

25 Davey S, Davey A, Srivastava A, Sharma P, Health P. Privatization of medical education in India: a health system dilemma. Int J Med (Dubai) 2014;4(1):17-22

26 Many Indian states have less than 10 psychiatrists: these govt figures tell a shocking story. Available at: https://www.thenewsminute.com/article/many-indian-states-have-less-10psychiatrists-these-govt-figures-tell-shocking-story-69940. Accessed March 19, 2020

27 Raman AV, Björkman JW. Public/private partnership in health care services in India. Available at: http://medind.nic.in/haa/ t08/i1/haat08i1p62.pdf. Accessed March 19, 2020
28 NIMHANS PROSPECTUS 2019-20. Available at: http:// nimhans.ac.in/wp-content/uploads/2019/09/NIMHANS_ Prospectus-2019-20_Final-Version_1.pdf. Accessed March 19, 2020

29 Bandawar M, Narasimha VL, Chand P. Use of digital technology in addiction disorders. Indian J Psychiatry 2018;60(8, Suppl 4): S534-S540

30 Mehrotra K, Chand P, Bandawar M, et al. Effectiveness of NIMHANS ECHO blended tele-mentoring model on Integrated Mental Health and Addiction for counsellors in rural and underserved districts of Chhattisgarh, India. Asian J Psychiatr 2018;36:123-127

31 India MCo. Conversion of Postgraduate diploma seats to degree seats; 2019 A Medical Council of India. Conversion of Postgraduate diploma seats to degree seats. Available at: https://www.mciindia.org/CMS/HINDI/wp-content/uploads/ 2017/10/Circular-Surrender-of-Diploma-1.pdf

32 Kakunje A, Punnoose VP, Ponnusamy KP, Mysore AV, Daniel SJ. Revisiting postgraduate (PG) psychiatry training in India. Indian J Psychol Med 2019;41(4):380-387

33 India State-Level Disease Burden Initiative Mental Disorders Collaborators. The burden of mental disorders across the states of India: the Global Burden of Disease Study 1990-2017. Lancet Psychiatry 2020;7(2):148-161

34 van Ginneken N, Maheedhariah MS, Ghani S, Ramakrishna J, Raja A, Patel V. Human resources and models of mental healthcare integration into primary and community care in India: Case studies of 72 programmes. PLoS One 2017;12(6):e0178954

35 Manjunatha N, Thyloth M, Sathyanarayana Rao TS. The rise of super (?sub)-specialties courses in psychiatry: Is India ready for it! Indian J Psychiatry 2013;55(4):401-402

36 Sood R. Medical education in India. Med Teach 2008; 30(6):585-591 